RESEARCH NOTE

\section{Susceptibility of Helicobacter pylori to Metronidazole in a Brazilian Population}

\section{Marco Salazar/ ${ }^{+}$, Isabel Abalém, Claude Solari/*, Charisse Rodriguez**, Luiz Luna** $^{* *}$}

Laboratório de Enterobactérias, Departamento de Bacteriologia, Instituto Oswaldo Cruz, Av. Brasil 4365, 21045-900 Rio de Janeiro, RJ, Brasil *Hospital Universitário Gaffrée e Guinle, UNIRIO, Rio de Janeiro, RJ, Brasil **Setor de Endoscopia Digestiva, Hospital do Andaraí, Rio de Janeiro, RJ, Brasil

Key words: Helicobacter pylori - susceptibility metronidazole

Helicobacter pylori is strongly associated with gastritis, ulcer disease and has recently been recognized as a probable cofactor in the development of gastric cancer ( $\mathrm{F}$ Mégraud \& H Lamouliatte 1992 Dig Dis Sci 37: 769-772, E Raws \& G Tytgat 1990 Lancet $i$ : 1233-1235, J Kang et al. 1990 Gut 31: 476-480, A Nomura et al. $1991 N$ England J Med 325: 1132-1136). Although the mechanism of pathogenicity has not yet been fully clarified, there is evidence to suggest that patients with Helicobacter-associated peptic ulceration can be cured by antimicrobial treatment directed towards eradication of this microrganism (R Hopkins et al. 1996 Gastroenterol 110: 1244-1252). This eradication is best achieved with triple antimicrobial therapy. Among agents used in the therapy of infection are metronidazole, bismuth salts, furazolidone, ciprofloxacin, tetracycline, amoxicillin, erythromycin, roxithromycin, azithromycin, and clarithromycin (L Resende et al. 1993 Braz J Med Biol Res 26: 1279-1289, G Cederbrant et al. 1994 J Antimicrob Chemother 34: 1025-1029, L Klein \& S Tanaka 1995 Ann Rep Med Chem 30: 151158, Hopkins et al. loc. cit.). However emergence of strains of $H$. pylori-resistant to antimicrobial agents, specially metronidazole, represents a draw-

${ }^{+}$Corresponding author. Fax: +55-21-280.0754

Received 29 March 1996

Accepted 27 August 1996 back to therapeutic regimens (European Study Group on Antibiotic Susceptibility of Helicobacter pylori 1992 Eur J Clin Microbiol Infect Dis 11: 777-781). In our country, the frequent use of metronidazole could select resistant strains to this agent. Various methods of susceptibility testing have determined resistance to metronidazole and include agar dilution, disk diffusion and the E-test (G Rubinstein et al. 1994 J Antimicrob Chemother 34: 409-413, P Midolo et al. 1995 Diagn Microbial Infect Dis 21: 135-140).

The objective of this study was to determine the Minimum Inhibitory Concentrations (MICs) of our strains to metronidazole.

Forty strains of $H$. pylori isolated from dyspeptic Brazilian patients who were not treated with any antimicrobial therapy for $H$. pylori infection and were referred to endoscopy service (Andaraí Hospital, Rio de Janeiro) were studied. Strains were stored in plastic vials at $-70^{\circ} \mathrm{C}$ in sterile defibrinated sheep blood before being tested.

MICs to metronidazole for $H$. pylori strains grown in Brucella agar (Difco) supplemented with $10 \%$ defibrinated sheep blood and $0.004 \%$ 2, 3, 5 tripheniltetrazolium chloride (TTC-Difco) (D Queiroz et al. 1987 J Clin Microbiol 25: 23782379) in a microaerophilic atmosphere for $72 \mathrm{hr}$, were determined by E-test (AB Biodisk, Sweden). E-test strip with antimicrobial concentrations from 0.002 to $32 \mathrm{mg} / \mathrm{l}$ were assayed. The bacterial inoculum was prepared in Brucella broth (Difco) and adjusted to McFarland standard 0.5. The plates were streaked with non-toxic swab three times, rotating the plate approximately 90 degrees each time to ensure a distribution of inoculum. The MIC was defined as the lowest concentration at which there was completely inhibited growth. The breakpoint of $\geq 8 \mathrm{mg} / \mathrm{l}$ was used to indicate resistance (Y Glupczynski et al. 1990 Lancet 335: 976977).

The prevalence of metronidazole-resistant strains was $72.5 \%$ (29/40). Twenty nine strains showed MIC $\geq 32 \mathrm{mg} / \mathrm{l}$ whereas 11 strains showed MIC between 0.016 to $2 \mathrm{mg} / \mathrm{l}$. In the present study, the rate of metronidazole resistance was similar to that observed in a previous Brazilian study (64.7\%) (D Queiroz et al. 1993 Am J Gastroenterol 88: 322323), where the MIC values to metronidazole were not mentioned.

On the other hand, comparing our results to the multicentre European survey on metronidazole resistance (European Study Group on Antibiotic Susceptibility of Helicobacter pylori loc. cit.) we observe much higher resistance levels in Brazil than in Europe. The resistance there varied from 7 to $49 \%$, having the non-Caucasian groups the most elevated percentage of resistance. Considering the 
MIC $\geq 32 \mathrm{mg} / \mathrm{l}$, we found $100 \%$ of resistent strains while the European Group detected 88.5\% (108/ 122).

Due to its effective local (D Edwards 1986 Biochem Pharmacol 35: 53-58) and even systemic activities (S Loft et al. 1988 Clin Pharmacol Ther 43: 420-428), reaching the gastric cells, metronidazole has been considered a complement to the treatment of $H$. pylori infection (Hopkins et al. loc. cit.). The occurrence of metronidazole-resistant $H$. pylori strains has been reported to be related to the earlier use of nitroimidazoles (T Borody et al. 1988 Gastroenterol 94: A43, M Becx et al. 1990 Lancet $i: 539-540)$. In our country these resistant strains can possibly be explained by frequent use of this drug in the treatment of gynecological, parasitic and urological infections; moreover, free distribution and reduced costs in hospitals and medical centers indicate common availability for the population.

Considering the present results in our country, it is recommendable to perform susceptibility testing of $H$. pylori strains to antimicrobial agents before initiating treatment in order to avoid failure.

Acknowledgments: to Evaldo Soares da Silva and Sergio Alves Azevedo for technical support. 